\title{
Clinical significance of RCAS1 as a biomarker of ovarian cancer
}

\author{
KENZO SONODA $^{1}$, SHINGO MIYAMOTO ${ }^{2}$, FUSANORI YOTSUMOTO ${ }^{2}$, HIROSHI YAGI $^{1}$, \\ MANABU NAKASHIMA ${ }^{3}$, TAKESHI WATANABE ${ }^{4}$ and HITOO NAKANO ${ }^{1}$ \\ ${ }^{1}$ Department of Obstetrics and Gynecology, Graduate School of Medical Sciences, Kyushu University, Fukuoka 812-8582; \\ Departments of ${ }^{2}$ Obstetrics and Gynecology, Faculty of Medicine, and ${ }^{3}$ Clinical Pharmacology, Faculty of Pharmaceutical \\ Sciences, Fukuoka University, Fukuoka 814-0180; ${ }^{4}$ Unit for Immune Surveillance Research, \\ RIKEN Research Center for Allergy and Immunology, Yokohama 230-0045, Japan
}

Received September 25, 2006; Accepted November 21, 2006

\begin{abstract}
Expression of RCAS1 (receptor-binding cancer antigen expressed on SiSo cells) is associated with advanced disease of various malignancies including ovarian cancer. Proteolytic cleavage of RCAS1 at extracellular domains (ectodomain shedding) yields soluble RCAS1. Although RCAS1 can induce apoptosis in normal peripheral lymphocytes, its clinical significance and biologic function in ovarian cancer patients are unclear. Here, we evaluated serum RCAS1 concentrations to clarify its clinical significance and biologic activity in ovarian cancer. Via ELISA, we measured serum RCAS1 concentrations in samples from 75 healthy blood donors and 97 patients, 36 with ovarian benign tumor and 61 with ovarian cancer. We correlated via statistical means the RCAS1 values with patients' clinicopathologic variables. We assessed inhibition of growth of K562 cells, which express the putative RCAS1 receptor, via WST-1 assay of serum samples to clarify RCAS1's biologic activity. Ovarian cancer patients had significantly higher serum RCAS1 concentrations than did healthy blood donors and ovarian tumor patiens $(\mathrm{P}<0.05)$. RCAS1 level was significantly different according to histologic subtype for both ovarian tumor and cancer patients $(\mathrm{P}=0.0266$ and 0.0074 , respectively). RCAS1 values were also significantly associated with response to treatment $(\mathrm{P}<0.001)$. The WST-1 assay showed that patients' serum induced K562 cell growth inhibition, but this effect partially recovered after immunodepletion of RCAS1 $(\mathrm{P}=0.0074)$. RCAS1 may be a biomarker of ovarian cancer by virtue of its ability to predict results of treatment and inhibit immune cell growth.
\end{abstract}

Correspondence to: Dr Kenzo Sonoda, Department of Obstetrics and Gynecology, Graduate School of Medical Sciences, Kyushu University, Maidashi 3-1-1, Higashi-ku, Fukuoka 812-8582, Japan

E-mail: kenzo@gynob.med.kyushu-u.ac.jp

Key words: ovarian cancer, ELISA, ectodomain shedding, biologic marker, apoptosis

\section{Introduction}

Among gynecologic malignancies in Western countries, ovarian cancer is the most frequent cause of death $(1,2)$. Because of the anatomic location of ovaries deep in the pelvis, ovarian cancers typically cause few symptoms until they are large or have disseminated. Three quarters of patients thus present with International Federation of Gynecology and Obstetrics (FIGO) criteria stage III or IV disease, i.e. with metastases in the abdomen or at distant sites. For these patients, the 5-year survival rates are $<30 \%$. In contrast, the small proportion of patients diagnosed with stage I disease have a 5 -year survival rate $>90 \%$.

To help improve the clinical outcome of ovarian cancer patients, several serum markers have been manufactured and characterized. Cancer antigen 125 (CA125) has a well-defined and validated role for monitoring ovarian cancer (3). However, the sensitivity of CA125 is too low for the antigen to be used as a population-based screening marker for early detection and diagnosis. Therefore, novel biomarkers that can deliver the required sensitivity for both early detection and monitoring of treatment warrant development.

A number of investigations have utilized both genomic and proteomic technologies to discover genes, gene products and proteins that may identify ovarian cancer biomarkers $(4,5)$. Chatterjee et al used a combination of high-throughput selection and a protein array-based serologic profiling system to search for diagnostic biomarkers of ovarian cancer (6). Receptor-binding cancer antigen expressed on SiSo cells (RCAS1) was identified as one of the antigens that may be a useful diagnostic marker for early detection of this disease, especially in high-risk populations.

RCAS1, a membrane protein that is detected by 22-1-1 antibody (7), is released by means of ectodomain shedding. It acts as a ligand for a putative receptor in different human cell lines and on normal peripheral lymphocytes. RCAS1 inhibits the growth of receptor-expressing cells in vitro and induces apoptotic cell death of lymphocytes near cancer cells in patients with uterine cervical cancer (8). Reports have documented strong expression of RCAS1 in uterine and ovarian malignancies $(9,10)$, with expression being significantly related to progression, invasion, and overall survival of uterine cervical and endometrial cancers (11-15). Akahira et al reported 
Table I. Relation between serum RCAS1 values and histologic subtype for patients with benign ovarian tumors.

\begin{tabular}{lccr}
\hline $\begin{array}{l}\text { Histologic } \\
\text { subtype }\end{array}$ & $\begin{array}{c}\text { No. of } \\
\text { patients }\end{array}$ & $\begin{array}{c}\text { RCAS1 concentration } \\
(\mathrm{U} / \mathrm{ml} \text {, mean } \pm \text { SEM })\end{array}$ & P-value \\
\hline $\begin{array}{l}\text { Dermoid cyst } \\
\begin{array}{l}\text { Endometriotic } \\
\text { cyst }\end{array}\end{array}$ & 10 & $4.57 \pm 1.06$ & 0.0266 \\
$\begin{array}{l}\text { Serous } \\
\text { cystadenoma }\end{array}$ & 7 & $5.50 \pm 1.38$ & \\
$\begin{array}{l}\text { Mucinous } \\
\text { cystadenoma }\end{array}$ & 6 & $6.34 \pm 1.90$ & \\
\begin{tabular}{l} 
Fibroma \\
\hline
\end{tabular} & 3 & $3.11 \pm 0.20$ & \\
\hline
\end{tabular}

significantly higher RCAS1 expression in tumors with serous histology and in advanced disease in epithelial ovarian cancer (16). Although RCAS1 is thought to play an important role in ovarian cancer, the serum RCAS1 level has not yet been investigated.

To clarify whether RCAS1 is in fact a biomarker of ovarian cancer, we studied i) serum RCAS1 concentrations in patients with benign or cancerous ovarian tumors and compared these values with those for healthy blood donors, ii) the correlation between serum RCAS1 values and clinicopathologic variables, iii) the relation between serum RCAS1 values and results of medical treatment, and iv) the inhibition of in vitro growth of RCAS1 receptor-expressing cells.

\section{Materials and methods}

Patients and serum samples. Serum samples from patients with benign or cancerous ovarian tumors were collected at the Department of Obstetrics and Gynecology, Kyushu University Hospital, between April 2003 and December 2005. The mean ages of patients with benign tumors and those with cancerous tumors were 43 years (range of 16-78 years) and 51 years (range of 17-80 years), respectively. Tables I and II provide clinicopathologic data for these patients. The FIGO staging system was used to assign stages to the cancerous tumors. Histologic subtype and grade of resected tumor specimens were evaluated by using slides of the specimens.

The 36 patients with benign tumors underwent salpingooophorectomy. Of the 61 patients with ovarian cancer, 54 were treated by surgery with platinum-containing chemotherapy. Four patients had only surgery, and three received only platinum-based chemotherapy.

Controls consisted of serum samples from 75 healthy female blood donors whose mean age was 42 years (range of 21-70 years).

Informed consent was obtained from all subjects, and the study protocol was approved by the ethics committee of Kyushu University.

Enzyme-linked immunosorbent assay (ELISA). Serum samples were stored at $-20^{\circ} \mathrm{C}$ until analysis. We measured serum concentrations of RCAS1, in triplicate, by means of an ELISA

Table II. Relation between serum RCAS1 values and clinicopathologic variables for patients with ovarian cancer.

\begin{tabular}{|c|c|c|c|}
\hline $\begin{array}{l}\text { Clinicopathologic } \\
\text { variable }\end{array}$ & No. of patients & $\begin{array}{l}\text { RCAS1 concentration } \\
(\mathrm{U} / \mathrm{ml} \text {, mean } \pm \mathrm{SEM})\end{array}$ & P-value \\
\hline
\end{tabular}

\begin{tabular}{lr}
\hline Stage & \\
I & 24 \\
II & 7 \\
III & 17 \\
IV & 13
\end{tabular}

Histologic subtype

$9.22 \pm 1.97$

$16.13 \pm 6.38$

$11.52 \pm 3.46$

$13.80 \pm 4.87$

Serous adenocarcinoma

Endometrioid adenocarcinoma

Clear cell adenocarcinoma

Mucinous adenocarcinoma

Germ cell tumor

Carcinosarcoma

Grade $^{\mathrm{a}}$

G1

G2
0.0074

$9.38 \pm 2.18$

$16.40 \pm 3.45$

$6.22 \pm 1.12$

$21.88 \pm 8.44$

$3.89 \pm 0.42$

$22.02 \pm 14.65$

$12.70 \pm 2.73$

$9.70 \pm 3.31$

$10.93 \pm 3.79$

${ }^{\mathrm{a}}$ Grade was determined for patients with epithelial ovarian cancer. 
kit (MBL Co., Nagoya, Japan), according to the manufacturer's instructions. The RCAS1 ELISA kit had been applied in earlier investigations of the clinical significance of RCAS1 in uterine cancer (17). The sensitivity of the RCAS1 assay is $0.008 \mathrm{U} / \mathrm{ml}$. We obtained serial measurements of serum RCAS1 concentrations for 32 patients whose tumor sizes clearly decreased $(n=16)$ or increased $(n=16)$ after treatment, the sizes being determined by computed tomography.

Tetrazolium salt (WST-1) assay. We performed this assay to analyze the biologic function of secreted RCAS1. WST-1 is cleaved to soluble formazan dye by succinate-tetrazolium reductase, which is part of the mitochondrial respiratory chain and is active in viable cells. The amount of formazan dye depends directly on the number of metabolically active cells; the greater the enzyme activity, the more formazan dye is produced. K562 cells express a putative receptor for RCAS1 (7), so inhibition of cell growth by cancer patients' serum can be measured in K562 cells.

In this assay, $1 \times 10^{4} \mathrm{~K} 562$ cells were seeded in a 96-well plate (Becton-Dickinson, San Diego, CA). Samples of serum with an RCAS1 level higher than $5 \mathrm{U} / \mathrm{ml}$ that were obtained from 48 patients, and samples of serum from 75 blood donors were added to wells to a final concentration of $75 \%$. WST-1 was added after $72 \mathrm{~h}$ of culture, according to the manufacturer's instructions (Dojindo, Kumamoto, Japan). Incubation continued for $3 \mathrm{~h}$, and then absorbency at $450 \mathrm{~nm}$ was measured via a microtiter plate reader (Bio-Rad Laboratories, Hercules, CA). Each assay was performed in triplicate. The control was absorbency determined after K562 cell culture with $10 \%$ fetal bovine serum.

Immunodepletion of RCAS1. Immunodepletion of RCAS1 from serum was achieved by the following method. Concentrated 22-1-1 hybridoma cell supernatant (9) was used to prepare anti-RCAS 1 antibody by salting out with ammonium sulfate. A sample of $200 \mu \mathrm{l}$ of serum was then incubated for $1 \mathrm{~h}$ with $20 \mu \mathrm{l}$ of 22-1-1 supernatant, after which $10 \mu \mathrm{g}$ of goat anti-mouse IgM antibody (Pierce, Rockford, IL) was added, followed by $1 \mathrm{~h}$ of incubation, addition of $30 \mu \mathrm{l}$ of protein $\mathrm{G}$ (Pierce), and another $1 \mathrm{~h}$ of incubation. The temperature for each incubation step was $4^{\circ} \mathrm{C}$. Final centrifugation of the serum sample was at 15,000 rpm for $10 \mathrm{~min}$; protein $\mathrm{G}$ was removed. After this immunodepletion process, the serum was used for the WST-1 assay.

We also used the same immunodepletion process in a preliminary study with concentrated SiSo cell culture supernatant. We added 5-30 $\mu 1$ of 22-1-1 supernatant to $200 \mu 1$ of SiSo cell culture supernatant that contained RCAS 1 at a concentration of $120 \mathrm{U} / \mathrm{ml}$. We obtained efficient removal of RCAS1 from $200 \mu 1$ of SiSo cell culture supernatant via immunoprecipitation with $20 \mu 1$ of the 22-1-1 supernatant (Fig. 1).

Statistical analysis. For each clinicopathologic variable, we performed the Fisher exact test to determine significant factors that affected serum RCAS1 values as univariate variables. We assessed the statistical significance of differences in RCAS1 concentration by using the Mann-Whitney test for two groups or the Kruskall-Wallis test for three or

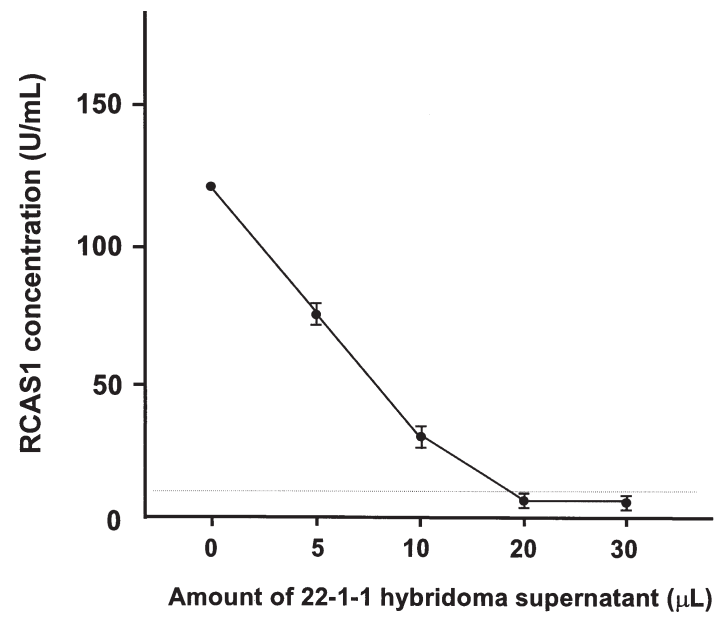

Figure 1. Immunodepletion of RCAS1 in concentrated SiSo cell culture supernatant was achieved by adding 22-1-1 supernatant (5-30 $\mu 1)$ to $200 \mu 1$ of the cell culture supernatant. The RCAS1 concentration in the supernatant was $120 \mathrm{U} / \mathrm{ml}$. Adding $20 \mu \mathrm{l}$ of anti-RCAS 1 antibody effectively removed RCAS 1 by causing immunoprecipitation. The dotted line indicates the mean RCAS1 value in serum from the healthy blood donors.

more groups. We evaluated the relationship between serum RCAS1 values and the progress of disease via Wilcoxon's test. P-values of $<0.05$ were taken as statistically significant.

\section{Results}

Serum RCAS1 concentrations. ELISA produced a mean $( \pm$ SEM) serum RCAS1 concentration in healthy blood donors of $4.37 \pm 0.25 \mathrm{U} / \mathrm{ml}$ (Fig. 2) (all values are given as means \pm SEM unless otherwise noted). Patients with benign ovarian tumors had RCAS1 values of $5.66 \pm 0.70 \mathrm{U} / \mathrm{ml}$, and patients with cancerous ovarian tumors had RCAS1 values of $11.63 \pm 1.74 \mathrm{U} / \mathrm{ml}$. The RCAS1 value was significantly higher for the cancer patients than for the healthy blood donors or the benign tumor patients $(\mathrm{P}<0.0001$ and $\mathrm{P}=0.0234$, respectively). The stage I ovarian cancer patients had a significantly higher RCAS1 level than healthy blood donors or benign tumor patients $(\mathrm{P}=0.0028$ and 0.0386 , respectively). Serum RCAS 1 values according to histologic subtype were significantly different for benign tumor patients $(\mathrm{P}=0.0266)$ (Table I). For ovarian cancer, values of secreted RCAS1 differed significantly according to histologic subtype $(\mathrm{P}=0.0074)$ (Table II). Patients with the mucinous histologic subtype of both benign and malignant tumors had high serum RCAS1 levels. Moreover, RCAS1 level was significantly higher in cancer patients than in benign tumor patients with mucinous or endometrioid histologic subtype $(\mathrm{P}=0.0250$ and 0.0092 , respectively). However, there was no significant difference in RCAS1 value between cancer and benign tumor patients concerning serous and germ cell tumor subtype ( $\mathrm{P}=0.5339$ and 0.2294 , respectively). The RCAS1 values also showed no significant correlation with clinical stage and grade in patients with ovarian cancer. The cancer patients had significantly higher serum RCAS 1 concentrations than did healthy blood donors, although the mean age of the healthy women was lower than that of the cancer patients. However, we here revealed no significant correlation between serum RCAS1 level and age in healthy 


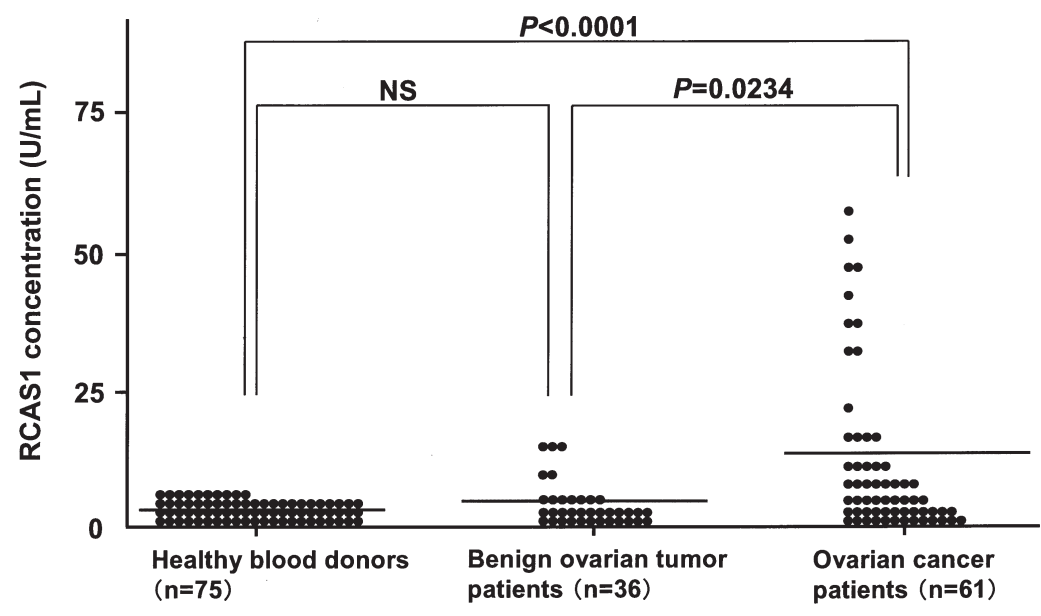

Figure 2. Serum RCAS1 values in patients with benign or cancerous ovarian tumors. The concentrations (means \pm SEM) of secreted RCAS1 were $4.37 \pm 0.25$, $5.66 \pm 0.70$ and $11.63 \pm 1.74 \mathrm{U} / \mathrm{ml}$ for healthy blood donors, benign tumor patients and cancer patients, respectively. The RCAS1 value was significantly higher for the cancer patients than for healthy blood donors or benign tumor patients $(\mathrm{P}<0.0001$ and $\mathrm{P}=0.0234$, respectively). For each group, the horizontal line indicates the mean RCAS1 value.
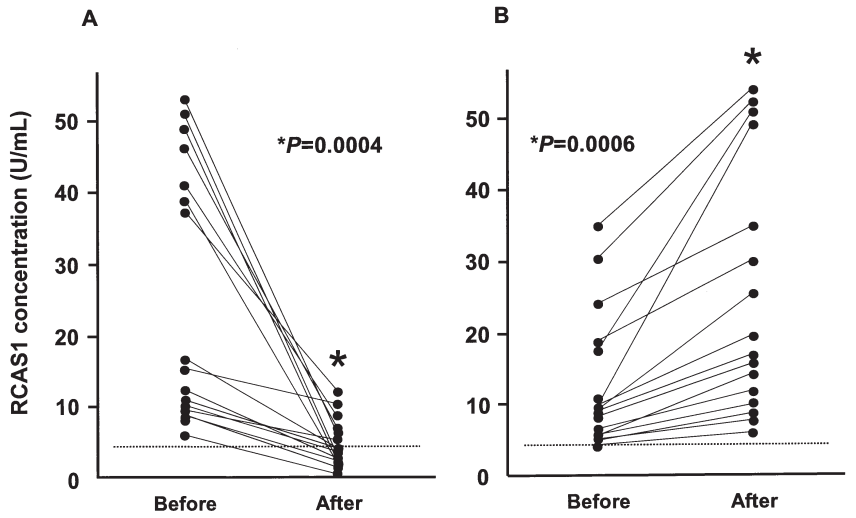

Figure 3. Serial serum RCAS1 measurements were obtained for 32 patients whose tumor sizes obviously decreased (A) $(n=16)$ or increased (B) $(n=16)$. These values correlated significantly with the change in tumor size from before to after treatment $(\mathrm{P}=0.0004$ and 0.0006 , respectively). The mean serum RCAS1 values in healthy blood donors are shown by horizontal dotted lines.

blood donors, benign tumor patients, and cancer patients ( $\mathrm{P}=0.8829,0.3322$ and 0.6027 , respectively).

Serial measurements of serum RCAS1 levels determined before and after treatment for 32 patients showed that the RCAS1 level was markedly reduced in patients with a positive response to treatment but increased in patients whose tumors clearly grew ( $\mathrm{P}=0.0004$ and 0.0006 , respectively) (Fig. 3).

Relation of RCAS1 secretion in peripheral blood to inhibition of growth of K562 cells. In the WST-1 assay, samples of cancer patients' serum in which the RCAS1 level was higher than $5 \mathrm{U} / \mathrm{ml}$, and serum samples from healthy blood donors were analyzed. Cancer patients, healthy blood donors, and benign tumor patients had serum absorbency (OD) values (mean \pm SD) at $450 \mathrm{~nm}$ of $1.07 \pm 0.04,1.41 \pm 0.04$ and $1.40 \pm 0.06$, respectively (Fig. 4). K562 cell growth was significantly inhibited by the cancer patients' serum compared with serum of healthy blood donors or benign tumor patients $(\mathrm{P}=0.0003)$.

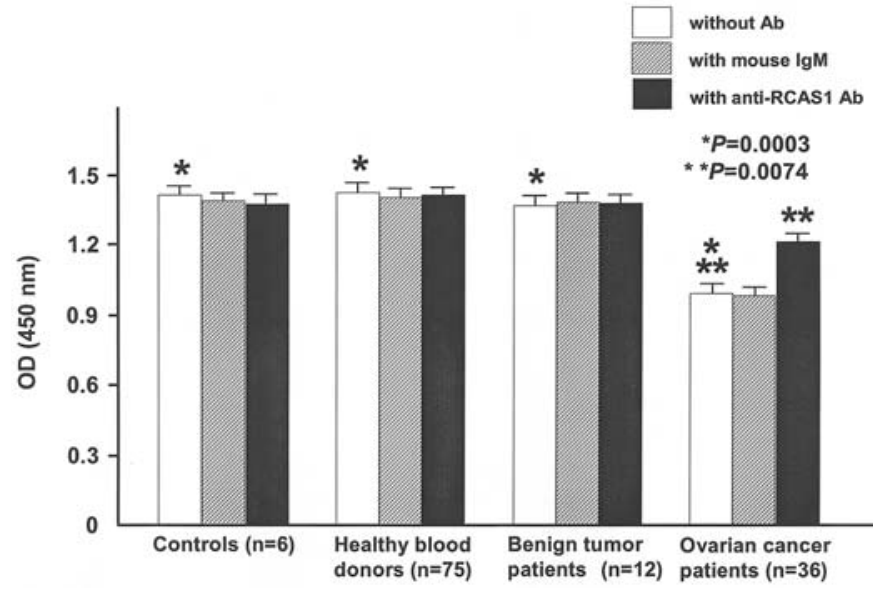

Figure 4. Inhibition of K562 cell growth by patients' serum. In the WST-1 test, cancer patients' serum in which the RCAS1 concentration was higher than $5 \mathrm{U} / \mathrm{ml}$, and serum from healthy blood donors were analyzed. Cancer patients' serum significantly inhibited the growth of K562 cells compared with the other groups $(\mathrm{P}=0.0003)$. After immunoprecipitation with antiRCAS1 antibody to remove RCAS1, the absorbency value of the cancer patients' serum significantly increased to $1.31 \pm 0.03(\mathrm{P}=0.0074)$.

Fig. 1 indicates that $120 \mathrm{U} / \mathrm{ml}$ RCAS1 was efficiently removed by adding $20 \mu \mathrm{l}$ of the $22-1-1$ supernatant. No RCAS1 concentrations in any serum sample was higher than $100 \mathrm{U} / \mathrm{ml}$, so we could assume that RCAS1 in all serum samples was completely removed by adding $20 \mu 1$ of 22-1-1 supernatant. After immunoprecipitation with anti-RCAS1 antibody to remove RCAS1, the absorbency value of serum from cancer patients significantly increased to $1.31 \pm 0.03(\mathrm{P}=0.0074)$ (Fig. 4). Serum from both blood donors and benign tumor patients, however, had an effect on K562 cell growth similar to that of controls (absorbency of $1.41 \pm 0.05$ ).

\section{Discussion}

The relationship between clinical stage and survival in ovarian cancer has long provided a rationale for efforts to improve 
outcome in patients by detection of early-stage disease. The last two decades have seen a major effort to evaluate the value of the tumor marker CA125 and ultrasound scanning to screen for ovarian cancer (4). Data from large prospective studies of ovarian cancer screening in the general population suggest that sequential multimodal screening has superior specificity and positive predictive value compared with ultrasound alone $(18,19)$. However, CA125 reportedly lacks specificity and provides an accurate assessment in only approximately $50 \%$ of ovarian cancer patients (20). Most patients with a normal CA125 value and no clinical evidence of disease at the completion of primary chemotherapy still have microscopic residual cancer (21). Therefore, another clinically useful biomarker would greatly enhance the ability to make management decisions during surveillance and treatment.

The development of new technologies continues to provide powerful methods for screening for ovarian cancer $(4,5)$. Chatterjee et al used a combination of high-throughput selection and protein array-based serologic detection of many antigens indicating the presence of cancer (6). One result was identification of RCAS1 as a useful diagnostic biomarker for early detection of ovarian cancer. RCAS1 was highly expressed in 22 of 30 stage I tumors, 26 of 29 late-stage tumors, but only 1 of 20 normal ovaries. We previously reported that RCAS1 was highly expressed in ovarian cancers but was not detected, by immunohistochemistry, in normal ovaries $(9,10,22)$. Akahira et al investigated RCAS1 expression in epithelial ovarian cancer and found significantly higher expression for cancers with serous histology and for advanced disease (16).

Our assessment here of serum RCAS1 concentrations in ovarian cancer found significantly higher levels in cancer patients than in healthy blood donors or patients with benign tumors. Though RCAS1 values showed no significant correlation with clinical stage in patients with ovarian cancer, even stage I ovarian cancer patients had significantly higher RCAS1 concentration than healthy blood donors or benign tumor patients. The mean age of these healthy blood donors was lower than that of the cancer patients, however, there was no significant correlation between serum RCAS1 level and age in healthy blood donors, benign tumor patients, and cancer patients. The RCAS1 level also correlated with histologic subtype and with the response to treatment. Here, patients with the mucinous histologic subtype of both benign and malignant tumors had high RCAS1 concentrations. This result agrees with published findings of immunohistochemical studies showing high expression of RCAS1 in mucinous ovarian tumors $(9,10)$.

We previously investigated serum RCAS1 values in patients with uterine cervical or endometrial cancer (17). We found that patients with uterine cancer had serum levels of RCAS1 that were significantly different compared with those of healthy female blood donors. A high concentration of RCAS1 in blood samples from patients with pancreatic or cholangiocellular carcinoma had also previously been reported (23-25). Measurements of serum RCAS1 levels were shown to aid diagnostic accuracy and estimation of tumor progression or therapeutic effect.

Mechanisms regulating RCAS1 production have not yet been clarified but may relate to proteolytic processing and certain characteristics of cancer. RCAS1 undergoes proteolytic cleavage by 12 - $O$-tetradecanoylphorbol 13 -acetate as
FasL and TNF- $\alpha$ are processed (11). Cancer cells often manufacture and secrete such molecules. The extracellular domain of various membrane proteins can be cleaved proteolytically, which causes the proteins to be released $(26,27)$. This proteolytic processing, or ectodomain shedding, can be demonstrated for growth factors, growth factor receptors, cell-adhesion molecules, extracellular matrix proteins, and other membrane proteins such as RCAS1. Ectodomain shedding of these proteins affects their biologic activities and is therefore an important regulatory process for the functioning of membrane proteins involved in cell-cell communication in development, cell differentiation, and tissue maintenance (28). Studies of shed tumor-derived FasL, as one example of such molecules, reported paracrine pro-apoptotic effects of FasL in the pancreatic tumor microenvironment. In addition, soluble FasL has systemic effects in cancer patients, because high levels are released into the bloodstream (29).

Although mechanisms of the regulation of RCAS1 expression and secretion remain unclear, one explanation may involve the aggressive characteristics of cancer. Induction of ectodomain shedding occurs after addition of peptide growth factors and activation of mitogen-activated protein kinase (30). Also, activated mitogenic signaling pathways may be associated with the aggressive behavior of ovarian cancer $(31,32)$. In cancer cells with aggressive potential, excess RCAS1 may therefore have a role in accelerated turnover of RCAS1 by means of ectodomain shedding. A few reports have found RCAS1 expression in normal uterine endometrium and gastric mucosa $(22,33)$, but the mechanisms of the control and function of RCAS1 expression in these tissues are still unclear. However, we showed here that the serum RCAS1 concentration was significantly higher in cancer patients than in healthy women, so the mechanisms of RCAS1 expression and shedding may differ in cancerous and normal tissues.

In this study, it was shown that cancer patients' serum induced K562 cell growth inhibition, with partial recovery after immunodepletion of RCAS1. So far RCAS1 has been reported to induce apoptosis in its putative receptor expressing cells including peripheral lymphocytes in vitro and in vivo $(7,8)$. Moreover, RCAS1 expression is associated with poor clinical outcome in gynecologic malignancies $(11,14,15)$. Collectively, this evidence suggests that RCAS1 may contribute to tumor progression in ovarian cancer patients. Actually, the absence of intratumoral $\mathrm{T}$ lymphocytes was reportedly associated with significantly worse survival in ovarian cancer (34).

Our current findings are the first to indicate that the serum RCAS1 concentration may predict the treatment results of ovarian cancer patients. We also correlated the serum RCAS1 concentration with inhibition of growth of receptor-expressing K562 cells. By clarifying the molecular mechanisms related to RCAS1 functioning in future studies, we may not only improve the possibility of early detection of ovarian cancer but also develop new treatments by targeting RCAS1.

\section{Acknowledgements}

This study was supported in part by a grant-in-aid for cancer research from the Ministry of Health and Welfare of Japan (nos. 16591669 and 18591835). This study was performed in part at the Station for Collaborative Research and at the 
Morphology Core, Graduate School of Medical Sciences, Kyushu University.

\section{References}

1. Landis SH, Murray T, Bolden S and Wingo PA: Cancer statistics. CA Cancer J Clin 49: 8-31, 1999.

2. Society American Cancer: Cancer Facts and Figures - 2005, American Cancer Society, Inc., 2005.

3. Meyer T and Rustin GJ: Role of tumour markers in monitoring epithelial ovarian cancer. Br J Cancer 82: 1535-1538, 2000.

4. Jacobs IJ and Menon U: Progress and challenges in screening for early detection of ovarian cancer. Mol Cell Proteom 3: 355-366, 2004.

5. Rapkiewicz AV, Espina V, Petricoin EF III and Liotta LA: Biomarkers of ovarian tumours. Eur J Cancer 40: 2604-2612, 2004.

6. Chatterjee M, Mohapatra S, Ionan A, Bawa G, Ali-Fehmi R, Wang X, Nowak J, Ye B, Nahhas FA, Lu K, Witkin SS, Fishman D, Munkarah A, Morris R, Levin NK, Shirley NN, Tromp G, Abrams J, Draghici S and Tainsky MA: Diagnostic markers of ovarian cancer by high-throughput antigen cloning and detection on arrays. Cancer Res 66: 1181-1190, 2006.

7. Nakashima M, Sonoda K and Watanabe T: Inhibition of cell growth and induction of apoptotic cell death by the human tumor-associated antigen RCAS1. Nat Med 5: 938-942, 1999.

8. Sonoda K, Miyamoto S, Hirakawa T, Yagi H, Yotsumoto F, Nakashima M, Watanabe T and Nakano H: Association between RCAS1 expression and microenvironmental immune cell death in uterine cervical cancer. Gynecol Oncol 97: 772-779, 2005.

9. Sonoda K, Nakashima M, Kaku T, Kamura T, Nakano H and Watanabe T: A novel tumor-associated antigen expressed in human uterine and ovarian carcinomas. Cancer 77: 1501-1509, 1996.

10. Razvi K, Sonoda K, Lee YS, Tham KF, Lim FK and Yong EL: A preliminary study of the immunohistochemical detection of a novel tumour marker, 22-1-1 antigen, in gynaecological cancer specimens. Ann Acad Med Singapore 28: 392-394, 1999.

11. Sonoda K, Miyamoto S, Hirakawa T, Yagi H, Yotsumoto F, Nakashima M, Watanabe $\mathrm{T}$ and Nakano $\mathrm{H}$ : Invasive potency related to RCAS1 expression in uterine cervical cancer. Gynecol Oncol 99: 189-198, 2005.

12. Sonoda K, Kaku T, Kamura T, Nakashima M, Watanabe T and Nakano H: Tumor-associated antigen 22-1-1 expression in the uterine cervical squamous neoplasias. Clin Cancer Res 4: 1517-1520, 1998.

13. Sonoda K, Kaku T, Hirakawa T, Kobayashi H, Amada S, Sakai K, Nakashima M, Watanabe T and Nakano $\mathrm{H}$ : The clinical significance of tumor-associated antigen RCAS1 expression in the normal, hyperplastic and malignant endometrium. Gynecol Oncol 79: 424-429, 2000.

14. Kaku T, Sonoda K, Kamura T, Hirakawa T, Sakai K, Amada S, Ogawa S, Kobayashi H, Nakashima M, Watanabe T and Nakano $\mathrm{H}$ : The prognostic significance of tumor-associated antigen 22-1-1 expression in adenocarcinoma of the uterine cervix. Clin Cancer Res 5: 1449-1453, 1999.

15. Sonoda K, Miyamoto S, Hirakawa T, Kaku T, Nakashima M, Watanabe T, Akazawa K, Fujita T and Nakano H: Association between RCAS 1 expression and clinical outcome in uterine endometrial cancer. Br J Cancer 89: 546-551, 2003.

16. Akahira JI, Aoki M, Suzuki T, Moriya T, Niikura H, Ito K, Inoue S, Okamura K, Sasano $\mathrm{H}$ and Yaegashi $\mathrm{N}$ : Expression of EBAG9/RCAS1 is associated with advanced disease in human epithelial ovarian cancer. Br J Cancer 90: 2197-2202, 2004.

17. Sonoda K, Miyamoto S, Hirakawa T, Yagi H, Yotsumoto F, Nakashima M, Watanabe T and Nakano H: Clinical significance of RCAS1 as a biomarker of uterine cancer. Gynecol Oncol (In press).
18. Menon U, Taalat A, Jeyerajah AR, Rosenthal AN, MacDonald ND, Skates SJ, Sibley K, Oram DH and Jacobs IJ: Ultrasound assessment of ovarian cancer risk in post-menopausal women with CA125 elevation. Br J Cancer 80: 1644-1647, 1999.

19. Jacobs IJ, Skates SJ, MacDonald N, Menon U, Rosenthal A, Davies R, Woolas AP, Jeyarajah AR, Sibley K, Lowe DG and Oram DH: Screening for ovarian cancer: a pilot randomized control trial. Lancet 353: 1207-1210, 1999.

20. Schwartz PE and Taylor KJ: Is early detection of ovarian cancer possible? Ann Med 27: 519-528, 1995.

21. Wong C, Dai ZM, Lele SB and Natarajan N: Comparison of CA125 after three courses of chemotherapy and results of second-look surgery. Eur J Gynaecol Oncol 21: 70-73, 2000.

22. Kawano Y, Kaku T, Sonoda K, Hirakawa T, Kobayashi H, Ohishi Y and Nakano H: Expression of RCAS1 in female genital organs. Int J Gynecol Pathol 24: 330-334, 2005.

23. Akashi T, Oimomi H, Nishiyama K, Nakashima M, Arita Y, Sumii T, Kimura T, Ito T, Nawata H and Watanabe T: Expression and diagnostic evaluation of the human-associated antigen RCAS1 in pancreatic cancer. Pancreas 26: 49-55, 2003.

24. Yamaguchi K, Enjoji M, Nakashima M, Nakamuta M, Watanabe T and Tanaka M: Novel serum tumor marker, RCAS1, in pancreatic diseases. World J Gastroenterol 11: 5199-5202, 2005.

25. Enjoji M, Nakashima M, Yamaguchi K, Kotoh K and Nakamuta M: Significance of RCAS1 antigen in hepatocellular, cholangiocellular and pancreatic carcinomas. J Gastroenterol Hepatol 20: 1143-1148, 2005.

26. Massague $J$ and Pandiella A: Membrane-anchored growth factors. Annu Rev Biochem 62: 515-541, 1993.

27. Rose-John S and Heinrich PC: Soluble receptors for cytokines and growth factors: generation and biological function. Biochem J 300: 281-290, 1994.

28. Izumi Y, Hirata M, Hasuwa H, Iwamoto R, Umata T, Miyado K, Tamai Y, Kurisaki T, Sehara-Fujisawa A, Ohno S and Mekada E: A metalloprotease-disintegrin, MDC9/meltrin- $\gamma / \mathrm{ADAM} 9$ and PKC $\delta$ are involved in TPA-induced ectodomain shedding of membrane-anchored heparin-binding EGF-like growth factor. EMBO J 17: 7260-7272, 1998.

29. Bellone G, Smirne C, Carbone A, Mareschi K, Dughera L, Farina EC, Alabiso O, Valente G, Emanuelli G and Rodeck U: Production and pro-apoptotic activity of soluble CD95 ligand in pancreatic carcinoma. Clin Cancer Res 6: 2448-2455, 2000.

30. Montero JC, Yuste L, Diaz-Rodrigues E, Esparis-Ogando A and Pandiella A: Mitogen-activated protein kinase-dependent and independent routes control shedding of transmembrane growth factors through multiple secretases. Biochem J 363: 211-221, 2002.

31. Hsu CY, Bristow R, Cha MS, Wang BG, Ho CL, Kurman RJ, Wang TL and Shih IM: Characterization of active mitogenactivated protein kinase in ovarian serous carcinomas. Clin Cancer Res 10: 6432-6436, 2004

32. Steinmetz R, Wagoner HA, Zeng P, Hammond JR, Hannon TS, Meyers JL and Pescovitz $\mathrm{OH}$ : Mechanisms regulating the constitutive activation of the extracellular signal-regulated kinase (ERK) signaling pathway in ovarian cancer and the effect of ribonucleic acid interference for ERK1/2 on cancer cell proliferation. Mol Endocrinol 18: 2570-2582, 2004.

33. Kubokawa M, Nakashima M, Yao T, Ito KI, Harada N, Nawata H and Watanabe T: Aberrant intracellular localization of RCAS1 is associated with tumor progression of gastric cancer. Int J Oncol 19: 695-700, 2001.

34. Zhang L, Conejo-Garcia JR, Katsaros D, Gimotty PA, Massobrio M, Regnani G, Makrigiannakis A, Gray H, Schlienger K, Liebman MN, Rubin SC and Coukos G: Intratumoral $\mathrm{T}$ cells, recurrence and survival in epithelial ovarian cancer. N Engl J Med 348: 203-213, 2003. 